\title{
CONCEPTOS FUNDAMENTALES DEL IMPUESTO GENERAL A LAS VENTAS
}

Main concepts of Valued Added Tax

Walker Villanueva Gutiérrez*

Pontificia Universidad Católica del Perú

Profesor de Derecho Tributario de la Facultad de Derecho de la PUCP. Profesor de la Maestría de Derecho Tributario de la PUCP y de la Maestría en Tributación y Política Fiscal de la Universidad de Lima. Socio de PPU abogados. ORCID iD: 0000-0002-4412-2363. Contacto: walker.villanueva@ ppulegal.com 


\section{Resumen:}

El presente artículo tiene como principal objetivo dar a conocer los aspectos más relevantes del Impuesto al Valor Agregado o, como se conoce en el Perú, el Impuesto General a las Ventas (IGV). Para ello, se presenta tanto la finalidad de los impuestos, como una breve descripción de los impuestos indirectos. Asimismo, se reconoce al principio de neutralidad como un concepto neurálgico para entender el impuesto. A partir de ello, se expone un enfoque desde los fundamentos económicos del impuesto, como el valor agregado y el consumo para, finalmente, y bajo dicha premisa, analizar su regulación jurídica, la cual utiliza conceptos del Derecho Civil.

\section{Abstract:}

The main purpose of this article is to present the most relevant aspects of the Value Added Tax (VAT) in Peru. For that purpose, the aim of taxes is explained, as well as a brief description of indirect taxes. Likewise, the principle of neutrality is recognized as a neuralgic concept to understand the VAT. Based on this, an approximation is made from the economic foundations of the tax, such as value added and consumption, to finally, and under this premise, analyze its legal regulation, which uses concepts of Private Law.

\section{Palabras clave:}

Impuesto General a las Ventas - Principio de neutralidad - Consumo Valor agregado - Contraprestación

\section{Keywords:}

Value Added Tax - Principle of neutrality - Consumption - Value Added - Compensation

\section{Sumario:}

1. Los impuestos gravan siempre la renta como única fuente de riqueza -2 . Impuestos directos e impuestos indirectos -3 . Breve historia de los impuestos indirectos -4 . Los conceptos económicos fundamentales del impuesto - 5. Principio de neutralidad -6. El concepto de consumo-7. El valor agregado y la contraprestación - 8. Conceptos jurídicos fundamentales del impuesto - 9. El nombre del impuesto: impuesto a las ventas o impuesto al valor agregado -10 . Conclusiones -11 . Lista de referencias 


\section{LOS IMPUESTOS GRAVAN SIEMPRE LA RENTA COMO ÚNICA FUENTE DE RIQUEZA}

La única manifestación de riqueza que gravan los impuestos es la renta acumulada. Los ciudadanos generan renta de diversas formas como medio de subsistencia para cubrir sus necesidades (empresa, trabajo, capital, plusvalías, especulación, apuestas, premios, juegos de azar, etc.). La renta generada se destina al consumo para la subsistencia de la persona y su familia, y también para cubrir consumos de lujo o suntuosos. El exceso de renta, si hubiera, se destina al ahorro.

Toda riqueza procede la renta y la renta se consume o se ahorra. Si se consume, vuelve a tributar en el impuesto que grave el correspondiente consumo. Si se ahorra, puede volver a tributar en el Impuesto sobre el Patrimonio. Y se ahorra y más adelante se consume, puede haber tributado primero en el Impuesto sobre la Renta, después en el impuesto el Patrimonio y más tarde en el correspondiente impuesto sobe el consumo. La riqueza es única y el desglose de distinto índices de capacidad económica y de diferentes impuestos no debe hacernos caer en la confusión que es mayor de lo que realmente es. Porque una cosa la midamos de distintas formas y en distintos momentos no dejar ser una sola cosa (López Espadafor, 2008, p. 7).

Debemos ser conscientes que, como señala Tipke:

[L]a experiencia nos ofrece un criterio general: los impuestos solo pueden obtenerse a partir de la renta (acumulada). Toda renta percibida que no es objeto de consumo para a ser renta acumulada o - en otras palabras - patrimonio... Todos los impuestos ... que hay y ha habido... son diversas manifestaciones del gravamen sobre la renta (acumulada). Por consiguiente, sólo existe una fuente impositiva: la renta acumulada. El legislador siempre se nutre de esta fuente por más que invente nuevos impuestos (Tipke, 2002, p. 32) ${ }^{1}$ [Énfasis agregado].

Si quisiéramos simplificar la recaudación tributaria, podríamos eliminar todos los impuestos y establecer un impuesto único sobre la renta que sea razonable, justo, equitativo y cubra las necesidades financieras del Estado. ¿Dónde está el problema? En nuestro impulso natural y egoísta como seres humanos de no pagar los impuestos que corresponden, lo que obliga al Estado a tener una estrategia pragmática para recaudarlos, comenzado por el impuesto por

\footnotetext{
"Potentially, income tax cast a wider net than a consumption tax because not all income is spent of consumption. Some income is saved and invested in assets. (...) if the only tax in an economy is a consumption, income saved and invested is not tax" (Holmes, 2000).
} 
antonomasia que es el impuesto sobre la renta, el cual requiere información detallada de las personas y capacidad efectiva de control del Estado, lo que es complejo en economías informales como la nuestra.

Como sabemos que el Estado tiene capacidad limitada para controlar que todos los ciudadanos contribuyan con el pago de su impuesto a la renta, se crea una segunda oportunidad para recaudar el impuesto a través de los gastos o consumos que realizan los ciudadanos, con la ventaja psicológica que las personas no son conscientes, ni sienten el pago del impuesto, porque este viene oculto en el precio de los bienes y servicios.

Este efecto puede apreciarse en la Ley del Impuesto General a las Ventas e Impuesto Selectivo al Consumo, que obliga a discriminar el Impuesto General a las Ventas (IGV) y el Impuesto Selectivo al Consumo (ISC) cuando se trata de ventas a sujetos del impuesto ${ }^{2}$, pero no cuando se trata de ventas a consumidores finales quienes son los que asumen el pago de los impuestos al consumo. Quiere decir que el efecto psicológico o ilusorio de no sentir el pago del impuesto está consentido por la ley.

Sin perjuicio de lo anterior, el legislador bien puede crear una ocasión adicional para recaudar el impuesto sobre la renta acumulada, si es que el ciudadano no consume o gasta, sino ahorra y acumula patrimonio, exigiendo, por ende, un impuesto sobre la renta ahorrada, sobre el patrimonio ahorrado.

\section{IMPUESTOS DIRECTOS E IMPUESTOS INDIRECTOS}

Explicada la razón de la existencia de distintos impuestos, el mundo de hoy se organiza sobre la base de los impuestos directos y de los impuestos indirectos. Los impuestos son directos porque afectan económicamente a la persona designada por la ley como obligada al pago del impuesto y son indirectos cuando el contribuyente traslada económicamente el impuesto a un tercero.

Como esta característica de los impuestos es contingente, esto es, que depende la voluntad de las partes, en el sentido que un impuesto directo se puede trasladar por acuerdo de partes y un impuesto indirecto puede no trasladarse por el pacto de las partes y la elasticidad del precio de los productos o servicios, se propone una cualidad más estable para dicha diferenciación y se sostiene que los impuestos indirectos constituyen una manifestación indirecta

2 El artículo 38 segundo párrafo de la Ley del IGV e ISC dispone que "En las operaciones con otros contribuyentes del impuesto se consignará separadamente en el comprobante de pago correspondiente el monto del impuesto". 
de la capacidad económica de los ciudadanos para pagar impuestos, mientras que los impuestos directos constituyen una manifestación directa en el sentido que el patrimonio y la renta son indicativos directos de la riqueza acumulada por un ciudadano, mientras que el consumo o gasto no son indicadores directos y concluyentes de la riqueza del ciudadano que podría consumir bienes y servicios con dinero prestado.

La distinción entre impuestos directos e indirectos es importante, porque en el mundo de hoy los Estados que tienen más capacidad de fiscalización y control de sus ciudadanos basan su recaudación en los impuestos directos complementados por impuestos indirectos, por cuanto los primeros se consideran más justos en la medida que permiten medir la capacidad económica o riqueza de que disponen los ciudadanos para el pago de los impuestos, mientras que en los países en vías de desarrollo con menor capacidad de control, los impuestos indirectos tienen mayor peso en la recaudación, complementados por impuestos directos.

A fin de ilustrar lo señalado, en países OCDE la recaudación de los impuestos al consumo está en $32.7 \%$ y en Latinoamérica $49.5 \%$, mientras que el Impuesto a la Renta y las contribuciones sociales están alrededor de $60 \%$ en países OCDE y en Latinoamérica en $44 \%^{3}$.

\section{BREVE HISTORIA DE LOS IMPUESTOS INDIRECTOS}

Los impuestos indirectos como se conciben hoy (como un impuesto de carácter general y abstracto sobre las ventas y los servicios) son una creación del siglo XX. Su antecedente histórico fue el impuesto de alcabala recaudado en Castilla en 1342 (Grapperhaus, 2009, p. 27) sobre bienes muebles en general; sin embargo, durante la Edad Media fue preponderante la recaudación de regalías, de derechos cuyo fundamento radicada en el concepto del dominio del rey sobre los bienes inmuebles (carreteras, ríos navegables, puertos), propiedades y derechos (administración de justicia, derechos de pesca, peaje sobre la sal, derechos sobre la mitad de los tesoros encontrados en los dominios del rey), así como sobre la explotación de minas de plata, derechos sobre las tierras sin cultivo, derecho de caza, derecho de afincamiento de bastardos y extranjeros, entre otros.

La evolución histórica demuestra que los impuestos al consumo han evolucionado de la imposición específica de bienes a la imposición general de

3 Véase en: OCDE, et al., 2019. 
bienes como un impuesto abstracto sobre la venta de bienes y posteriormente se han incorporado algunos servicios específicos y finalmente los servicios en general. En la actualidad, se debe incorporar el comercio digital de bienes y de servicios en sus diversas modalidades: Business 2 Business (B2B), Business 2 Consumer (B2C) y Business 2 Goverment (B2G).

La evolución del impuesto abstracto sobre las ventas o transacciones hacia el impuesto al valor agregado fue idea del alemán Friedich Von Siemens, quien propuso en 1919 la sustitución del impuesto sobre las ventas por el impuesto sobre el valor añadido tomando en cuenta el mayor valor de los bienes en cada etapa, lo que ennoblecería su recaudación.

Sin embargo, Maurice Laure propició en Francia que se sustituyera el impuesto sobre las ventas por un impuesto al valor agregado que fue aprobado en 1954, a fin de superar los inconvenientes de la acumulación del impuesto sobre las ventas y la distorsión de la competencia por la integración que propiciaba el impuesto sobre las ventas. El efecto acumulación produce que el impuesto se convierta en precio de los productos de la siguiente fase de comercialización, y a su vez, se aplique el impuesto sobre impuesto, lo que generaba el incentivo de integrarse y reducir etapas en la cadena de producción y comercialización.

\section{LOS CONCEPTOS ECONÓMICOS FUNDAMENTALES DEL IMPUESTO}

El IGV es un impuesto construido sobre la base del principio de neutralidad, lo que le otorga una cualidad única al impuesto: los contribuyentes o deudores tributarios no asumen la carga económica del impuesto, no pagan el impuesto con su propio dinero, sino con el dinero que recaudan o cobran de sus clientes.

Los empresarios que ofrecen bienes y servicios en el mercado son los contribuyentes del impuesto, son los deudores tributarios frente a la Superintendencia Nacional de Aduanas y de Administración Tributaria (SUNAT). Los responsables de pagar el impuesto, sin embargo, no pagan al Estado con su propio dinero, sino lo recaudan de sus clientes.

En términos sencillos, los empresarios que venden bienes y servicios trasladan el IGV a sus clientes a través del precio. Por ejemplo, si un empresario A vende un producto a 100, agrega 18 por IGV, y su precio total es 118. A su vez, si los clientes son empresarios tienen derecho a que el IGV pagado en sus compras (18 en el ejemplo) les sea reembolsado por el Estado a través del denominado crédito fiscal. El crédito fiscal viene a ser un derecho de crédito sui generis que permite que el IGV pagado en las compras cuando el 
comprador es empresario sea restado del IGV generado por las operaciones gravadas con el impuesto ${ }^{4}$.

En el ejemplo, el Estado cobraría 18 y, a su vez, reembolsaría 18, de modo que recaudaría cero. Sin embargo, el empresario B que compra a 100, vende con un margen de ganancia, supongamos que lo hace a 150, de modo que, traslada un IGV de 27 en el precio total de su producto que viene a ser 177 . Por su parte, el Estado le reembolsa 18 (el IGV de las compras) y recauda un monto neto de 9 . El monto neto recaudado de 9 viene a ser el $18 \%$ del valor agregado que añade el empresario B que es de 50, pues compró a 100 y vendió 150.

Así, B como proveedor de bienes y servicios traslada el IGV (27 en el ejemplo) a través de sus facturas como parte del precio de venta y como comprador empresario tiene derecho a deducir el IGV que le han trasladado en sus facturas de compras como crédito fiscal (18 en el ejemplo). Si el comprador fuera consumidor final no tiene derecho de reembolso del IGV de compras (27 en el ejemplo) y compraría el producto a un precio de 177.

Los elementos fundamentales que pueden apreciarse de este ejemplo sencillo son los siguientes:

- Neutralidad: El principio de neutralidad que viene a ser el corazón del impuesto en el sentido que el empresario proveedor de bienes y servicios tiene derecho de crédito fiscal respecto del IGV pagado en sus compras y tiene derecho de trasladar el IGV sobre la venta de sus bienes y servicios. Aquí se aprecian dos relaciones jurídicas: la relación de repercusión del impuesto (traslado del IGV) y la relación de crédito fiscal, que permiten que el IGV recaudado por el Estado (27-18=9) no afecte económicamente al empresario, porque el IGV de compras le es reembolsado y el IGV de ventas se traslada a los clientes.

- Valor agregado: El empresario organiza los medios humanos y materiales para suministrar bienes y servicios en el mercado y su actividad empresarial agrega valor económico para hacer posible que los bienes o servicios estén disponibles en el mercado. En el ejemplo, el impuesto se recauda en función al valor agregado que se genera en cada etapa. Pasando a otro ejemplo, si el fabricante agrega valor por 100 y el Estado recauda 18, el

$4 \quad$ La Decisión N 599, en su artículo 2 define el derecho al descuento o crédito fiscal como aquel que tiene el sujeto pasivo de restar de los impuestos generados por las operaciones gravadas que realice los impuestos repercutidos o trasladados por la compra o importación de bienes o utilización de servicios. 
mayorista agrega valor por 80 y el Estado recauda 14.4 y si el minorista agrega valor por 60, y el Estado recauda 10.8. La virtud de este modo de imposición es que el Estado asegura la recaudación durante la cadena empresarial en función al valor agregado que cada quien aporta hasta llegar al consumidor final. El Estado al final del día recauda el impuesto sobre la suma de valores agregados durante la cadena empresarial. En el ejemplo, la suma de valores agregados F100 +M80+m60 hacen un total de 240 y el Estado recauda en total 43.2.

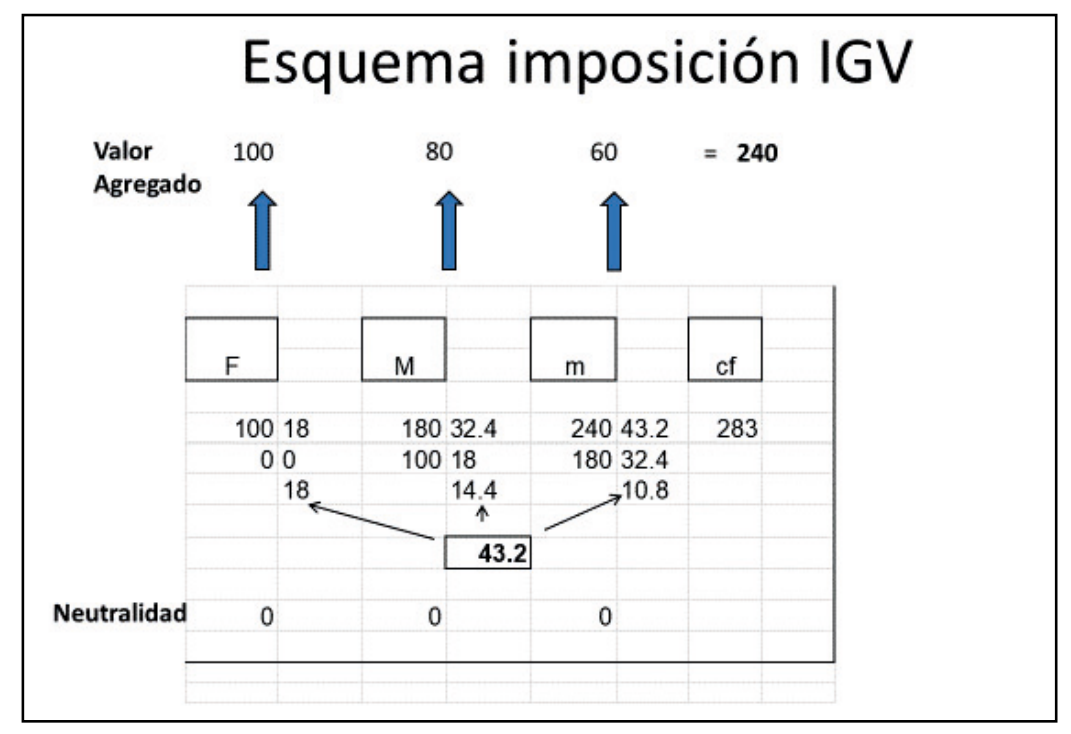

Figura 1. Fuente: Elaboración propia.

- Consumidor final: En el supuesto anterior donde el consumidor final compra el producto final a 177 que incluye el IGV de 27 que proviene de la tasa del impuesto sobre la suma total de valores agregados de toda la cadena (100 de la primera etapa y 50 de la segunda etapa). De modo que, el consumidor final paga el IGV sobre el valor total de la cadena de producción y comercialización. Si la cadena empresarial comprende menos empresarios habrá menos valor agregado y si la cadena comprende más empresarios habrá más valor agregado y según ello habrá menos o más IGV por pagar por parte del consumidor final. 
- Control administrativo y procedimental del impuesto: El control cruzado es esencial en el impuesto. Considerando que el IGV de las compras es reembolsable, se debe asegurar que el proveedor ha pagado efectivamente el impuesto, pues de lo contrario, se le estaría reembolsando dinero que no ha ingresado a las arcas del Estado. En nuestro país, el control cruzado se realiza con la exigencia de sustentar las compras con los comprobantes de pago correspondientes, la anotación de los comprobantes de pago en el registro de compras y con la implementación de los mecanismos de recaudación del impuesto, asegurando el IGV en manos del comprador de los bienes (retenciones del impuesto) o el cobro adelantado del impuesto en manos de proveedores confiables para el Estado (percepción del impuesto) o condicionando el uso del crédito fiscal al pago del impuesto en cuentas bancarias intangibles (detracciones).

En suma, los empresarios durante la cadena de producción y comercialización no asumen la carga económica del impuesto y simétricamente los consumidores finales soportan el total del impuesto vía el precio final de los productos o servicios que se ponen a su disposición. El IGV es una bola caliente que se pasa de mano a mano, de empresario a empresario, hasta que el consumidor final lo recibe con la carga total del impuesto y se quema con la bola caliente.

\section{PRINCIPIO DE NEUTRALIDAD}

El principio de neutralidad se manifiesta en tres conceptos diferentes en el funcionamiento del IGV:

i. El empresario, durante la cadena de comercialización, no asume costo económico por concepto del IGV, lo que no afecta a su margen bruto de utilidad, aunque se generen costos financieros. Jurídicamente, la neutralidad se materializa a través de la repercusión y la deducción del crédito fiscal. Ben Terra y Julie Kajus hacen una excelente definición del IGV en términos de neutralidad:

The VAT is a paradox: (using the credit method) the VAT is a tax in which those who believe themselves exempt are taxed, and those who believe themselves taxed, are generally exempt... whoever grasps the meaning of this, will not have any trouble understanding VAT (2009, p. 299).

La repercusión del impuesto se refleja en la obligación del sujeto del impuesto de discriminar en el comprobante de pago el IGV que grava la operación. A su vez, el comprobante de pago es el título indispensable para 
que el usuario ejerza su derecho a deducir el crédito fiscal. No hay crédito fiscal sin comprobante de pago que discrimine el IGV correspondiente. La repercusión está regulada en el artículo 38 de la Ley del IGV, que dispone

En las operaciones con otros contribuyentes del Impuesto se consignará separadamente en el comprobante de pago correspondiente el monto del Impuesto. Tratándose de operaciones realizadas con personas que no sean contribuyentes del Impuesto, se podrá consignar en los respectivos comprobantes de pago el precio o valor global, sin discriminar el Impuesto [Énfasis agregado].

La repercusión es una obligación con prestación de hacer, pues el sujeto pasivo está obligado a consignar el IGV en forma discriminada en los comprobantes de pago que emite. La repercusión es una obligación que surge del artículo 38 de la Ley del IGV. Es una obligación de carácter legal que se impone a los sujetos de la relación contractual, el proveedor como deudor de consignar en forma separada el IGV y el usuario o comprador como acreedor de exigir el cumplimiento de la prestación de hacer.

La traslación del impuesto es el fenómeno en virtud del cual el contribuyente del impuesto, el obligado al pago del impuesto por mandato de ley, deriva la carga económica del impuesto hacia otro sujeto. El artículo 38, tercer párrafo de la Ley dispone que "el comprador del bien, el usuario del servicio (...) están obligados a aceptar el traslado del impuesto". Se trata de una norma imperativa que obliga al comprador o usuario del servicio a aceptar el traslado económico del impuesto, lo cual puede regularse en forma expresa y diferente en el contrato civil celebrado entre las partes.

El crédito fiscal es una obligación legal que tiene como acreedor al sujeto del impuesto y como deudor al Estado. Asimismo, su cualidad jurídica permite al acreedor oponer la compensación automática y legal contra la obligación tributaria, para lo cual, el sujeto debe probar su derecho y ejercerlo en la forma que establece la ley, siendo importante destacar que nuestra ley ha privilegiado el principio de sustancia sobre forma jurídica en cuanto a los deberes formales referidos al registro de compras.

ii. La neutralidad impositiva busca que el impuesto no altere o influya en las decisiones de consumo de los bienes y servicios y, por lo tanto, no tenga ningún efecto sobre la asignación eficiente de los recursos en la economía. No se cumpliría este principio si, por efecto de la imposición, se produjera un cambio en las decisiones que los individuos habrían agotado en ausencia de ella (Emilfork, 1999, p. 26). 
iii. La neutralidad que deriva del principio de igualdad en el sentido que las transacciones que comparten la misma naturaleza deben tener el mismo trato fiscal. La neutralidad en este sentido tiene un doble aspecto: un aspecto objetivo, en el sentido que las transacciones idénticas o similares deben tener el mismo trato fiscal, y un aspecto subjetivo, en el sentido que sujetos que ejercen la misma actividad empresarial deben ser tratados en la misma forma.

La neutralidad objetiva se manifiesta, por ejemplo, en la definición amplia del hecho gravado servicios y la neutralidad subjetiva en la definición amplia del sujeto contribuyente del impuesto que debe incorporar a los sujetos que ofrecen bienes y servicios en el mercado compitiendo entre sí.

\section{EL CONCEPTO DE CONSUMO}

Los impuestos afectan la riqueza generada por los ciudadanos. Vienen a ser una participación del Estado proporcional, razonable y justa sobre la riqueza generada.

Los impuestos no pueden crear o inventar riqueza donde no existe, el legislador puede usar su ingenio para etiquetar el impuesto que corresponda con nombres diferentes (impuesto selectivo al consumo, impuesto a los juegos, impuesto a las transacciones financieras, impuesto al rodaje, etc.), pero en último término los impuestos recaen sobre la renta que generan los ciudadanos en distintos momentos, al momento de su generación -impuesto a la renta-, en el momento de su consumo - impuesto al consumo- y en el momento de su ahorro -impuestos al patrimonio-.

Como señala López Espadafor,

[E]l consumo no es totalmente ajeno a la renta, pues es la renta - o el patrimonio (como renta acumulada) - la que se destina al consumo. Por la renta se tributa al obtenerla, se tributa al ahorrarla al mantenerla dentro del patrimonio y se tributa al destinarla al consumo... (2008, p. 37).

Los impuestos que se recaudan al momento de la generación de la renta se denominan impuestos sobre la renta. Ahora, si la renta fue de 100 y el impuesto de $15 \%$, se tiene un remanente de $85 \%$. Ese remanente se vuelve a gravar cuando el ciudadano consume bienes o servicios (impuesto general a las ventas) o cuando el ciudadano ahorra ese remanente en propiedades (impuesto predial, impuesto vehicular), ocurriendo una doble imposición o hasta una triple imposición, si el ciudadano después de pagar su impuesto a la 
renta ahorra y paga el impuesto el patrimonio o propiedad y luego vende todo o parte de su patrimonio y lo consume pagando el IGV.

El IGV es un impuesto que se exige con ocasión del consumo de bienes y servicios por los ciudadanos. Se entiende que el ciudadano exterioriza una capacidad económica a través de dicho consumo. El consumo de bienes y servicios es la capacidad económica (la capacidad contributiva) que se pretende gravar con el impuesto. Se trata de exigir el impuesto al consumidor final que adquiere bienes y servicios, en cuanto su capacidad de consumo revela que dispone de recursos económicos suficientes.

Sin embargo, jurídicamente, la hipótesis de imposición que grava la ley no es el consumo que realiza el consumidor final, sino las ventas y servicios empresariales suministrados por las empresas, lo que otorga una cualidad única al IGV, por cuanto la capacidad contributiva que se pretende gravar (el consumo) no constituye el hecho gravado.

Esta cualidad única del impuesto genera la discusión técnica de si se trata de un impuesto a las transacciones o un impuesto al consumo, y creo que la pregunta no está bien formulada, puesto que el IGV es un impuesto cuya finalidad es gravar el consumo - en ese sentido, es un impuesto al consumo-, pero la formulación legal de la hipótesis de imposición no deja dudas de que es un impuesto sobre las ventas y servicios empresariales y, en ese sentido, es un impuesto a las transacciones.

Ahora bien, los operadores del derecho, cuando interpretan la norma y la construcción de sus significados plausibles, tienen como límite la letra de la ley; no se pueden construir significados más allá de los que toleran los límites razonables de la letra escrita de la norma. Veamos un ejemplo: si las empresas efectúan la venta de sus activos fijos, la conclusión no podría ser que la venta de un bien de inversión no está gravada con el impuesto porque no se está vendiendo bienes de consumo o porque el bien en cuestión no haya sido generado por la actividad empresarial del sujeto que genera valor agregado. La ley grava la venta de bienes muebles cuando su vendedor es una entidad que ejerce actividad empresarial, a pesar de que no esté vendiendo bienes destinados al consumo ${ }^{5}$.

El artículo 9.1. de la Ley del IGV dispone que son sujetos del impuestos los que efectúen actividad empresarial cuando efectúen ventas en el país de bienes afectos, presten servicios afectos, efectúen ventas afectas de bienes inmuebles, sin importar que sean operaciones habituales propias de su giro de negocios, así un estudio de abogados si vende sus computadoras estará obligada a pagar el IGV, aunque su actividad de valor agregado se dirija a la prestación de servicios legales y no a la venta de computadoras. 
Como hemos apreciado, si bien el consumo no es la hipótesis de imposición, el consumo tiene una influencia determinante en el diseño técnico y legal del impuesto en los siguientes aspectos:

\subsection{Comercio internacional de bienes y de servicios}

En el comercio internacional, las exportaciones de bienes y servicios no se gravan con los impuestos al consumo porque su consumo ocurre en el mercado extranjero.

En la exportación de bienes, la acreditación del consumo definitivo en el mercado extranjero se entiende producida con el embarque físico de los bienes en el punto de origen y con la declaración de aduanas de destinar los bienes al consumo definitivo en el mercado extranjero; mientras que, en la exportación de servicios se debe probar con todos los elementos de prueba disponibles y pertinentes que el consumo del servicio se ha producido en territorio extranjero.

Simétricamente, en el país donde se consumen los bienes y servicios provenientes del extranjero se exige el impuesto al consumo sobre la importación de los bienes y de los servicios. Tratándose de bienes provenientes del extranjero, el primer hecho gravado con el impuesto es la importación definitiva de los bienes, porque solo después de ella pueden consumirse legalmente en el mercado nacional. La importación de servicios se denomina utilización de servicios en nuestra legislación y grava los servicios proporcionados por no domiciliados siempre que el consumo o empleo de los servicios ocurra en el territorio nacional.

Nuestra ley también ha regulado la adquisición de bienes intangibles provenientes del extranjero como importación de bienes. En este caso, el impuesto se exige cuando el consumo o empleo de los bienes intangibles ocurre en el territorio peruano.

Esta misma idea se aplica al comercio digital de bienes y servicios que según la propuesta de la OCDE (International VAT Guidelines) ${ }^{6}$ aplicable al comercio

6 International VAT/GST Guidelines Value Added Tax (VAT; also known as Goods and Services Tax, under the acronym GST in a number of OECD countries) has become a major source of revenue for governments around the world. Some 165 countries operated a VAT at the time of the completion of the International VAT/GST Guidelines in 2016, more than twice as many as 25 years before. As VAT continued to spread across the world, international trade in goods and services has also expanded rapidly in an increasingly globalized economy. One consequence of these developments has been the greater interaction between VAT systems, along with grow- 
internacional de servicios e intangibles, debe regirse por el principio de imposición en destino propiciando la competencia leal entre proveedores nacionales y extranjeros que deben generar la misma carga fiscal para el consumidor.

\subsection{El concepto de bienes muebles}

El IGV prevé como hipótesis de imposición la venta de bienes muebles en el país. El concepto de bien mueble para propósitos del IGV difiere del que existe en el Derecho Civil, porque existen determinados bienes muebles que no son bienes de consumo, sino bienes de inversión. En efecto, los títulos valores, valores mobiliarios, acciones y los bonos, no son bienes muebles para efectos del IGV, porque no son susceptibles de consumo final. Son bienes de inversión sobre los que no debe recaer el impuesto cuya vocación es gravar el consumo y no las transacciones que representen decisiones de inversión.

\subsection{El concepto de constructor}

La venta de inmuebles gravada con el IGV requiere que el vendedor sea constructor, no basta ser empresario. La condición de constructor tiene como fundamento técnico la distinción entre inmuebles que son bienes de consumo e inmuebles que son bienes de inversión, gravándose únicamente los primeros. Se considera que los inmuebles son bienes de consumo cuando existe un empresario constructor que se dedica habitualmente a construir y vender inmuebles en el mercado, mientras que, si el vendedor no es constructor, se entiende que el inmueble no ha sido construido para venderlo sino para propio uso del vendedor por lo que representa un bien de inversión.

\subsection{Las operaciones gratuitas}

En un impuesto al valor agregado donde el sujeto organiza una actividad económica para ofrecer bienes y servicios y obtener una rentabilidad, las ope-

ing risks of double taxation and unintended non-taxation in the absence of international VAT co-ordination. The International VAT/GST Guidelines now present a set of internationally agreed standards and recommended approaches to address the issues that arise from the uncoordinated application of national VAT systems in the context of international trade. They focus in particular on trade in services and intangibles, which poses increasingly important challenges for the design and operation of VAT systems worldwide. They notably include the recommended principles and mechanisms to address the challenges for the collection of VAT on cross-border sales of digital products that had been identified in the context of the OECD/G2O Project on Base and Erosion and Profit Shifting (the BEPS Project). These Guidelines were adopted as a Recommendation by the Council of the OECD in September 2016. 
raciones gratuitas parecieran estar fuera de contexto, pues el valor agregado se genera a través de operaciones onerosas.

Sin embargo, es importante señalar que, desde el punto de vista del derecho positivo, el IGV es un impuesto a las transacciones (ventas o servicios) cuya finalidad es gravar el consumo de bienes y servicios. En ese sentido, las transacciones constituyen la causa instrumental para gravar el consumo final de bienes y servicios.

Considerando esta idea esencial, las operaciones gratuitas que no guardan relación con la actividad empresarial y respecto de las cuales el IGV de compras se ha deducido como crédito fiscal, generaría una desigualdad impositiva a favor de los consumidores de bienes y servicios que recibirían a título gratuito estos bienes y servicios, sin asumir la carga económica del impuesto.

Así, las operaciones a título gratuito se gravan con el impuesto, porque el empresario realiza transferencias de propiedad a título gratuito que no son necesarias para su actividad empresarial, por ejemplo, cuando regala mercadería a sus trabajadores para consumo de sus familias, cuando regala bienes por el cumpleaños o la boda de sus trabajadores.

En estos casos el empresario ha computado el crédito fiscal de los bienes que está regalando y, por lo tanto, los trabajadores beneficiados con estos regalos consumirían los bienes sin pagar IGV, lo que afectaría el principio de igualdad, porque habría consumidores que no pagarían el IGV.

A fin de igualar las condiciones entre consumidores finales que compran y consumidores finales que reciben los bienes como regalo, la ley exige el pago del IGV al empresario que realiza los regalos reputándolo como consumidor final y disponiendo que el IGV no se traslade al beneficiado ${ }^{7}$, ni tampoco que el IGV pagado pueda ser deducido como costo o gasto.

\section{EL VALOR AGREGADO Y LA CONTRAPRESTACIÓN}

La contraprestación es el precio de la venta de bienes o de la prestación de servicios, el cual debe incluir el IGV cuando se exhiben los precios al consumidor final. En el caso de una empresa productiva, por ejemplo, el precio es la suma de los costos de mercadería (40), los sueldos (20), los gastos diversos

Reglamento de la Ley del IGV, artículo 2.6. En ningún caso el impuesto que grave el retiro de bienes podrá trasladarse al adquirente de los mismos.

8 Ley del IGV, artículo 16. El impuesto no podrá ser considerados como costo o gasto por la empresa que efectúe el retiro de bienes. 
(20) más el margen de utilidad (20), y a dicha suma se agrega el IGV. Así el IGV afecta el valor total (100) y no solo el valor agregado.

El valor agregado es el costo de operación y la utilidad de cada empresario para ofrecer bienes y servicios en el mercado. El valor agregado se puede calcular de dos formas:

i. Método de sustracción: La diferencia entre las compras gravadas con el IGV (40 más 20) y las ventas gravadas con el impuesto (100), en el ejemplo sería de 40.

ii. Método de adición: La suma de los sueldos (20) más el margen de utilidad (20) sería de 40.

Como puede apreciarse, el valor agregado bajo el método de sustracción es equivalente resultado bajo el método de adición. En la mayoría de legislaciones del mundo, el valor agregado se calcula bajo el método de sustracción del impuesto de ventas, menos el impuesto de compras, porque es más sencillo de controlar y fiscalizar y además porque permite establecer períodos de recaudación más frecuentes (mensuales por ejemplo), mientras que el método de adición implicaría controlar los sueldos y el margen de utilidad del empresario y además siendo un impuesto que se debe trasladar al consumidor final, esta forma de cálculo sería inapropiada para posibilitar el traslado del Impuesto al consumidor final.

En el plano legal, las legislaciones del mundo establecen que la base imponible del impuesto sea equivalente al precio total de venta de los bienes y servicios y no se exige como requisito de la hipótesis de imposición (venta o servicio) que se exteriorice valor agregado.

Quiere decir lo expuesto, que el impuesto legalmente no grava el valor añadido porque la hipótesis de imposición no es el valor agregado, sino las ventas o los servicios empresariales que se gravan en función a su precio total.

Los hechos gravados con impuesto tienen una definición compleja, porque la concepción del impuesto es económica, dado que el impuesto fue creado y pensado por economistas, mientras que la regulación positiva lo aborda utilizando conceptos derivados del Derecho Civil, tales como: (i) la transferencia de propiedad, (ii) las transferencias o las prestaciones a título oneroso o a título gratuito, (iii) las transferencias de propiedad o prestaciones sobre bien mueble o inmueble, (iv) las prestaciones (de dar, de hacer y de no hacer) a cambio de una contraprestación (v) el arrendamiento, (vi) los contratos de construcción. Esta situación genera una tensión natural entre la finalidad económica del impuesto y su construcción jurídica en las legislaciones de cada país. 
Cosciani señalaba que las operaciones gravadas deberían limitarse a las que generan valor agregado.

Teniendo en cuenta que el impuesto es al valor agregado y tiende a gravar bienes y servicios de carácter final, aquella definición debe interpretarse en el sentido de que, para considerar una operación como prestación de servicios, debe ser de naturaleza tal que determine un valor agregado (transporte, seguro, publicidad, servicios de custodia, etc.) en un proceso de producción de bienes y servicios, con exclusión de cualquier otra operación (1969, p. 211).

En igual sentido, Blanco señala que "la noción de 'valor agregado' implica la necesidad de gravar operaciones económicas que realmente signifiquen un aumento de valor de los bienes y prestaciones a ser consumidos por las personas" (2001, p. 22).

Sin embargo, el valor agregado no constituye el hecho gravado del Impuesto, tampoco se exige que los hechos gravados generen valor agregado. En México, aunque la Ley del Impuesto al valor Agregado (IVA) no lo contempla expresamente se señala que

[L]os cuatros actos o actividades arriba mencionados (enajenación, prestación de servicios, uso o goce temporal de bienes o importaciones de bienes o servicios) son objeto del impuesto, en el sentido de ser signos de la existencia del verdadero objeto del impuesto, que es el hecho de agregar valor, y tan es así que hay múltiples resoluciones jurisdiccionales, sobre todo en materia de prestación de servicios independientes, en las que los tribunales rechazan o ratifican que tal acto o actividad debe o no pagar el impuesto, atendiendo no al hecho que tenga la naturaleza jurídica de los actos o actividades listados en este artículo, sino en función de si es un acto o actividad que agrega o no valor (Haro y Ocampo, 2011, pp. 1-2).

No obstante, el valor agregado tiene influencia determinante en el diseño técnico y legal del impuesto, en la regulación del IGV de compras como crédito fiscal, en la incorporación del Estado y las entidades sin fines de lucro como contribuyentes del IGV cuando organizan actividades similares a una actividad empresarial, en la inafectación del impuesto a las entidades financieras y bancarias porque técnicamente no se puede calcular el valor agregado, en la inafectación de las actividades de juegos y apuestas en las que el valor agregado debería calcularse por la diferencia entre el monto de las apuestas y los premios, como ocurre en Nueva Zelanda y que obligaría a tener una determinación del valor agregado por diferencias de bases imponibles y periódica, distinta a la técnica de imposición para la venta de bienes y servicios empresariales. 


\section{CONCEPTOS JURÍDICOS FUNDAMENTALES DEL IMPUESTO}

El impuesto se construye, en nuestra Ley, sobre la base del principio de neutralidad, del concepto de valor agregado y del concepto de consumo.

Como hemos visto, los conceptos económicos se plasman en las leyes del impuesto bajo conceptos propios del derecho civil, tales como la transferencia de propiedad, la prestación de dar, de hacer o no hacer, la contraprestación, las operaciones a título gratuito, los bienes muebles, los bienes inmuebles, el principio de unicidad, lo que produce tensiones entre los conceptos económicos y los conceptos jurídicos cuando estos son insuficientes o poco claros respecto de los fundamentos económicos del impuesto.

Los conceptos jurídicos nucleares del impuesto son los siguientes:

i. El derecho de crédito fiscal materializa la neutralidad económica para el empresario durante la cadena de comercialización de bienes o de servicios. La jurisprudencia judicial debe perfilar el derecho de crédito fiscal como esencial y fundamental para el funcionamiento del impuesto como un impuesto al consumo y evitar que se cuestione el derecho de crédito fiscal por anotaciones extemporáneas en el registro de compras electrónico, a pesar de que la Ley regula el principio de sustancia sobre forma jurídica (artículo 19 inciso c) de la Ley del IGV) y que el acto de anotar se puede realizar antes de que la SUNAT requiera la exhibición del registro de compras (Ley, artículo 2 de la Ley № 29215 modificada por el Decreto Legislativo $\left.\mathrm{N}^{\circ} 1116\right)$.

ii. El sujeto pasivo del impuesto, que como empresario organizador de actividades económicas pone a disposición del consumidor final los bienes y servicios que satisfacen sus necesidades. No interesa si el sujeto que organiza la actividad económica es el Estado, es una entidad sin fines de lucro, o un patrimonio autónomo (fondo de inversión, CAFAE), un colegio profesional, en la medida que todos estos sujetos compitan en el mercado deben estar sujetos al IGV. Por lo tanto, no es razonable que la jurisprudencia judicial haya determinado que las entidades de auxilio mutuo, a pesar de organizar actividades empresariales, no estén sujetos al impuesto.

iii. La contraprestación que se paga por el intercambio de bienes y servicios que constituye la base imponible del impuesto. Aquí es importante destacar el vínculo directo entre la operación gravada y el monto que se paga por dicha operación, de modo que las prestaciones que no derivan directamente de la venta o el servicio no están gravadas con el impuesto, como las utilidades que reparte el asociante al asociado que no derivan de la 
contribución efectuada por el asociado sino de su derecho a participar en las utilidades.

iv. La territorialidad del impuesto que grava las operaciones que tengan un nexo de conexión con el territorio nacional. Lo que constituye un reto para regular el criterio de localización de los servicios que puede giran en torno al sujeto (domicilio, lugar del establecimiento comercial, residencia habitual) o a la operación (uso o consumo en el país) y en el caso de la economía digital en función a presunciones de uso o consumo en el territorio de cada país (dirección IP, código SIM, dirección del emisor de la tarjeta de crédito, entre otros).

v. El principio de imposición en el país de consumo o de destino de las exportaciones de bienes y servicios, que implica no gravar las exportaciones y restituir el impuesto de las compras a favor del exportador, así como gravar las importaciones de bienes y de servicios provenientes del extranjero.

Dada la estrecha e íntima relación entre los principios económicos que hemos explicado y los institutos jurídicos que se construyen en la norma para lograr tales objetivos, es conveniente realizar siempre una interpretación finalista de la norma, procurando que los fundamentos técnicos y económicos del impuesto se respeten sobre la base de la interpretación del texto escrito de la norma jurídica.

\section{EL NOMBRE DEL IMPUESTO: IMPUESTO A LAS VENTAS O IMPUESTO AL VALOR AGREGADO}

La denominación del impuesto es diversa en las distintas jurisdicciones: Impuesto sobre las ventas (Colombia), impuesto general a las ventas (Perú), impuesto sobre las ventas y servicios (Chile), impuestos tipo valor agregado (Decisión $N^{\circ} 599$ de la Comunidad Andina), impuesto sobre valor añadido (Directiva N²006/112/CE de la Unión Europea).

La denominación de impuesto sobre el valor agregado o valor añadido destaca la recaudación del impuesto en función al valor agregado por cada empresario en la cadena de producción y comercialización conforme está explicado en la Figura 1, no se refiere a las hipótesis de imposición del impuesto que son las ventas y los servicios empresariales.

En cambio, la denominación de impuesto a las ventas o de impuesto a las ventas y servicios pone el acento en las hipótesis de imposición del impuesto. Considerando que una hipótesis de imposición más relevante del impuesto es la referida a los servicios, la denominación de impuesto a las ventas es incom- 
pleta e inexacta, porque omite mencionar un hecho gravado más relevante del impuesto (los servicios) que alcanza a la mayor cantidad de circulación de riqueza en el mercado.

Cossciani sostenía que el nombre genérico de Impuesto a las ventas atribuido a los distintos tipos de imposición, se explica porque las modalidades de imposición del consumo son el resultado de una lenta evolución de un mismo impuesto, que de imposición sobre determinados productos (generalmente mercaderías de lujo), poco a poco fue extendiéndose a todas las ventas, a todos los productos, y después ampliado para incluir a todos los servicios, para transformarse finalmente de un impuesto monofásico etapa final a un impuesto plurifásico sobre el valor agregado obtenido en cada etapa productiva (1969, pp. 2-3).

\section{CONCLUSIONES}

La tensión entre los fundamentos económicos del impuesto (neutralidad, consumo, valor agregado) y su regulación jurídica utilizando conceptos de derecho civil (venta, prestación, contraprestación, bien muebles o inmueble), debe conducirnos siempre a interpretar dentro de los límites del texto normativo, en función a la finalidad del impuesto, posibilitando la deducción del crédito fiscal que es el corazón del impuesto y, a su vez, que el consumidor final asuma la carga económica del impuesto.

El IGV tiene la complejidad que intervienen en su diseño, dos conceptos económicos complementarios, el valor agregado y el consumo, que generan el debate en relación a su naturaleza como un impuesto a las transacciones o como un impuesto al consumo, lo que nos parece una discusión estéril, pues pensamos que la finalidad del impuesto - causa final - es gravar la capacidad contributiva de consumo, para lo cual, el legislador se sirve de las transacciones (ventas o servicios) que generan valor agregado - como causa instrumental-. Nuevamente la interpretación de las normas debe efectuarse considerando la finalidad del impuesto con el límite del texto de la norma.

\section{LISTA DE REFERENCIAS}

Blanco, A. (2001). El Impuesto al Valor Agregado. Fondo de Cultura Económica. Cosciani, C. (1969). El impuesto al valor agregado. Depalma.

Emilfork Soto, E. (1999). El Impuesto al Valor Agregado. Editorial Jurídica Congreso. Gómez Haro, E. y Ocampo Medina, C. (2011). Estudio práctico del IVA. DoFiscal. 
Grapperhaus, F. H. M. (2009). Taxes trough the ages: a pictorial history - Tax tales: from the second millenium. IBFD.

Holmes, K. (2001). The concept of income: a multi-disciplinary analysis. IBFD.

López Espadafor, C. M. (2008). La no confiscatoriedad en la imposición sobre el consumo. Real Colegio de España en Bolonia.

OCDE, CEPAL, CIAT, BID y ALC. (2019). Estadísticas tributarias en América Latina y el Caribe. https://www.oecd.org/tax/tax-policy/brochure-estadisticas-tributarias-en-america-latina-y-el-caribe-2019.pdf.

Terra, B. y Kajus, J. (2009). A Guide to the European VAT Directives. IBFD.

Tipke, K. (2002). Moral tributaria del Estado y de los contribuyentes. Marcial Pons. 